\title{
Sticking Up for the Immune System Integrity: Should the Thymus Be Preserved During Cardiac Surgery?
}

\author{
Sara Ferrando-Martínez ${ }^{1,2}$, \\ M. Ángeles Muñoz-Fernández² and Manuel Leal ${ }^{1}$ \\ ${ }^{1}$ Laboratory of Immunovirology, Infectious Diseases Service, \\ HU Virgen del Rocío, Institute of Biomedicine of Seville (IBiS), Seville \\ ${ }^{2}$ Laboratory of Molecular Immuno-Biology, HGU Gregorio Marañón, Madrid
}

Spain

\section{Introduction}

Thymus is the site of maturation of $\mathrm{T}$ lymphocytes (TL) from bone marrow-derived precursors and, therefore, a major organ in the immune system generation and maintenance. Thymic function starts as early as during embryonic development and its activity is maximal after birth. However, maintain the high mitotic rate that the thymus shows during fetal life and first months of life is not cost-effective after childhood. A progressive atrophy, enhanced by adolescence, will lead to the thymic output exhaustion later on life. Accordingly, it has been long accepted that TL repertory is fixed during childhood and thymus activity is no longer necessary in either adulthood or elderly. Thymus anatomical situation, in the anterior mediastinum above the heart, situates it in the surgical field of important open heart procedures and is therefore routinely removed (partially or totally) in patients of any age. Thymic ablation impact during children's cardiac surgery is being studied to determine its potential influence in peripheral TL dynamics, despite only partial results are still available. Conversely, since adult and elderly thymic function is usually disregarded, thymic ablation during adult's cardiac surgery is accepted as appropriate and harmless. Recent results, however, indicate that thymus could have an active role in elderly immune system maintenance, increasing the importance of maximal preservation during any-age cardiac surgery. Thus, the aim of this chapter is to analyze the importance of thymic function during the different stages of life and to review current evidences of the potential clinical impact of both, early childhood and adulthood thymectomy.

\section{Overview of the human thymic gland}

\subsection{Embryonic development, anatomy and histology}

During embryonic development thymic epithelium and neighboring mesenchyme are derived from the cephalic region of the neural crest. Initially, thymus originates from the third pharyngeal pouch as two endodermic buds. Sprouts descend upon the superior mediastinum and will thereafter be fused as a V-shaped solid epithelial mass. Epithelium 
undergoes critical morphological changes and express the major histocompatibility class (MHC)-II complex at high levels as well as epidermal growth factor-like proteins that control several steps of tissue development and homeostasis, thus playing an important role in subsequent TL maturation processes. During the third gestation month thymus is colonized, via the bloodstream, by bone marrow-derived multipotential lymphoid stem cells (CFU-L), transforming the thymus in a lymphoepithelial organ. Under the inductive influence of modified thymic epithelial cells (TECs) lymphoid precursors mature in their passage through the thymus to be dumped back to peripheral blood as fully functional TL.

Developed thymus is a bilobed organ, surrounded by a connective-tissue capsule, located in the anterior mediastinum, just behind the sternum, above the heart and ahead the great vessels. Fibrous septa divide each thymic lobe into multiples smaller lobes. Thymocytes (lymphocytes undergoing maturation process in the thymus) locate heavily packed in the periphery of each lobe while the center is only sparsely populated. Therefore, a cortex and medulla region are usually identified despite there is no defined anatomical limitation. Cortex and medulla compose the true thymic epithelial space (TES), keratin-positive thymic epithelium that nourishes immature thymocytes, in which thymopoiesis actually occurs. In the human thymus a non-thymopoietic perivascular space (PVS), keratin-negative stroma, can also be found. In addition, non-lymphoid epithelial cells, bone marrow-derived macrophages and dendritic cells are spread over the thymus. Finally, Hassall's corpuscles, isolated tight whorls of epithelial cells located in the medullar region, are a thymic hallmark. Despite its function is still unclear, Interleukin (IL)-4 and IL-7 production could be its important contribution to thymocyte maturation and tuition. Vascular supply is rich in the thymus, and efferent lymphatic vessels drain into mediastinal lymph nodes. Young human thymus description and microphotography are showed in Figure 1A-B.

A fully functional thymus contains $10 \%$ of immature precursors and $15 \%$ of mature thymocytes waiting to reach the bloodstream as naive (antigen-inexperienced) TL. Remaining $75 \%$ of the thymocytes are in an intermediate maturation step (CD4+CD8+ double positive - DP - thymocytes) and undergoing selection processes. Approximately $99 \%$ of these immature thymocytes will not fulfilled the strict criteria to be safely poured to peripheral blood (extended information about the maturation process is provided in the next section) and endure programmed cell death in the cortical region, which is full of dying individual thymocytes. Phagocyted cells can also be found inside macrophages or cortical epithelial cells. Thus, the thymus has a dramatically high rate of both, mitosis and cell death. This situation of extensive proliferation and mass death cannot be cost-effectively maintained and thymus undergoes a chronically age-related atrophy as evolutionary energy-saving method. Atrophy starts from the first year of life (Steinmann et al., 1985) and is enhanced by hormonal changes during puberty (Chiodi, 1940). During the atrophy process the PVS (adipocytes, peripheral blood lymphocytes and stroma) increases, intensely diminishing the amount of TES. Loss of TES - it can be as low as $10 \%$ in elderly thymus together with architecture damage that breaks up the cortex/medulla structure leads to a less efficient thymopoiesis. Immature DP thymocytes percentages diminish and in situ TCR rearrangement is impaired (Sempowski et al., 2000). In addition, lymphoid component within the remaining TES also decreases in around 3\%/year during the first 35 to 45 years of life and 1\%/year thereafter (reviewed in Lynch et al., 2009). As a consequence, elderly thymuses are mostly adipocyte-filled PVS with isolated lymphoepithelial islets. Figure $1 \mathrm{C}$ D show a schematic representation and microphotography of an atrophied thymus. 
A)

B)
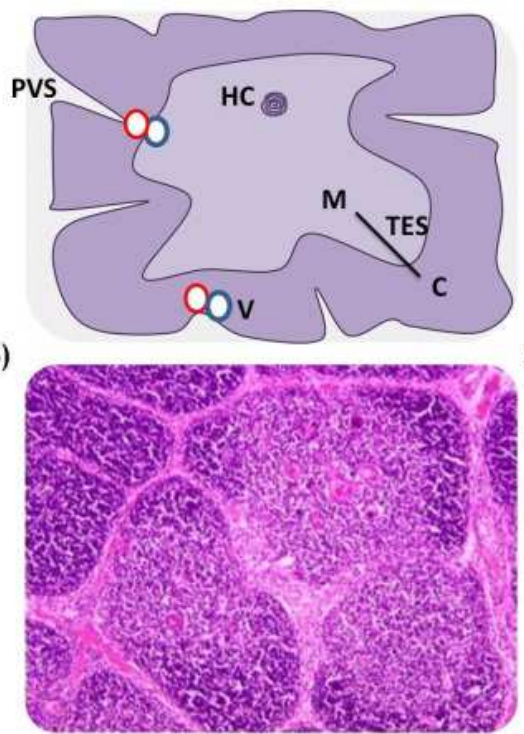

C)

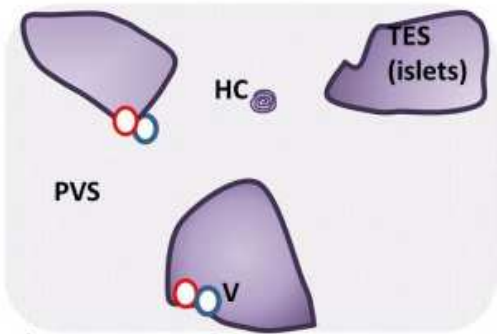

D)

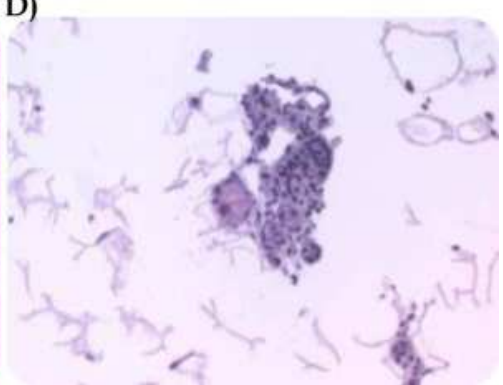

Fig. 1. Schematic representation and microphotography of young (A-B) and atrophied (C-D) thymus. $\mathrm{C}=$ Cortex; $\mathrm{HC}=$ Hassall' $\mathrm{s}$ corpuscles; $\mathrm{M}=$ Medulla; $\mathrm{PVS}=$ Perivascular space; TES $=$ Thymic epithelial space; $\mathrm{V}=$ blood vessels;

\subsection{T Lymphocyte (TL) maturation}

Thymus is the major site of maturation of TL. Bone marrow-derived lymphoid precursor entering the thymus commit to the $\mathrm{T}$ lineage. Maturation processes begin in the cortex and thymocytes move toward the medulla as they progress in the tuition program. Thymus is not only the provider of new mature naive TL to preserve the immune system integrity but also ensures that all departing cells are functional and non-self-reactive.

As shown in Figure 2 most immature cells of the T lineage enter the thymic cortex through the blood vessels. After a proliferation step Pro-T thymocytes, CD4-CD8- double negative (DN) irresponsive cells that still do not express the T cell receptor (TCR), start expressing the terminal deoxynucleotidyl transferase (TdT) enzyme, which adds random nucleotides to the TCR genomic sequence to increase lymphocyte diversity. Expression of the Rag-1 and Rag-2 proteins, necessary for the TCR rearrangement, marks the pre-T cell stage. Pre-T cells are still DN thymocytes. Beta chain of the TCR is rearranged at this stage. B-chain rearrangement success is tested in the cellular membrane using a pre-T a-chain. Expression of a functional $\beta$-chain triggers another proliferation round and the entry into the CD4+CD8+ double positive (DP) stage. Thymus atrophy diminishes TES lymphoid components by impairing this proliferation step. As a consequence, DP numbers, or DN to DP proliferation rates, are the best indicative of thymic functionality. DP thymocytes rearrange then the $\alpha$-chain of the TCR. Once a functional $\alpha \beta$ TCR protein is expressed, DP thymocytes start a strict scrutiny program. TCR affinity and avidity is checked from every thymocyte. Positive selection ensures that only cells presenting a functional TCR reach the next step. Thymocytes that do not receive a positive signaling thru a successful TCR 


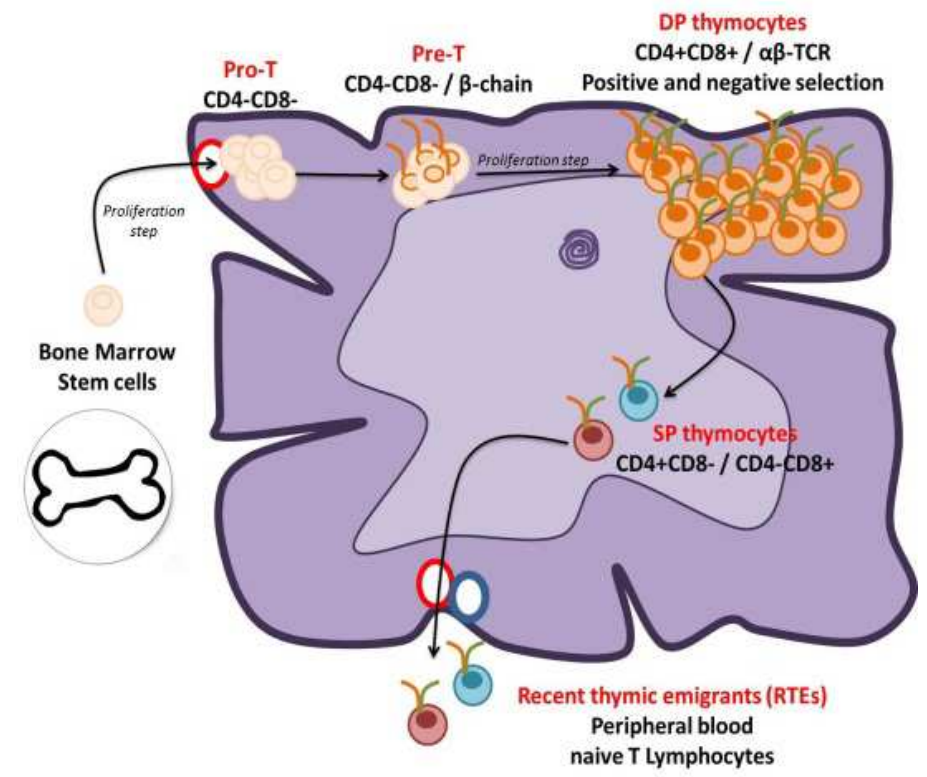

Fig. 2. Thymocyte maturation process.

recognition go to programmed cell death. Afterwards, a negative selection warrants that survivors do not have self-reactivity. Thymocytes with strong TCR signaling due to selfantigen recognition will be also directed to cell death. A small percentage of DP thymocytes, approximately $1 \%$, qualify to further maturation. Thymocytes migrate to the medullar space expressing a fully functional non-self-reactive TCR. CD4 and CD8 co-receptor expression is modulated in this stage and mature thymocyte are CD4 or CD8 single positive (SP) cells.

Thymocyte maturation and selection need the stimuli provided by the thymic microenvironment. TECs, bone marrow-derived macrophages and dendritic cells locate in the pathways of thymocyte migration, allowing physical interactions necessary for the maturation process. MHC class I and class II molecules (expressed by epithelial and dendritic cells); cytokines and chemokines (secreted by thymic stromal cells) provide signaling for selection process, stimulate thymocyte proliferation and coordinate the cortical to medullary transit. Therefore, non-lymphoid thymic cells play a crucial role in the immune system generation.

\subsection{Thymic function-related markers}

Study of thymic function is of great interest either to determine immune system impairment in lymphopenia scenarios or to monitor immune reconstitution. However, despite the necessity, lack of accurate measurement tools has hampered thymic output assessment. Due to its anatomical situation (in the anterior mediastinum, above the heart and ahead the great vessels) thymic biopsies are formally contraindicated and indirect measurements are needed. Thymic volume determination by thoracic computed tomography (CT) or magnetic resonance imaging (MRI) is an accurate indirect approximation and has been very useful to determine the role of thymic function in HIV-infected patients' immune reconstitution 
(Ruiz-Mateos et al. 2004). Nevertheless, both are expensive techniques where thymic inference needs specifically trained radiologists. Moreover, thoracic CT generates high levels of radiation. Thus, thymic function-related markers that could be determined from peripheral blood samples have usually been first choice for thymic output determination.

Naive TL quantification was the first proposed related-marker and is still being used. Controversy exist regarding the surface markers election that best discriminate the naive subset by flow cytometry. High expression of CD45RA, CCR7 and CD27 are commonly used to categorize this TL subset, and CD45RA+CD27+ or CD45RA+CCR7+ phenotypes seem to both be accurate enough to identify naive T cells (Ferrando-Martínez et al., 2010). However, naive TL are defined as mature lymphocytes that still have not find their specific antigen (non-experienced lymphocytes), disregarding whether they are recent thymic emigrants (RTEs) or long-lived cells. As a consequence, surface markers that could truthfully identify RTEs have been long chased. CD31-positive naive TL have very short proliferative history and are a RTE-enriched population (Junge et al., 2007). Moreover, protein tyrosine kinase 7 (PTK7)-expressing lymphcytes are proposed as precursor cells for later differentiation into mature naive TL (Haines et al., 2009). However, a marker that specifically characterizes mature thymocytes leaving the thymus is still missing.

$\mathrm{T}$ cell receptor excision circles (TREC) description was a milestone in thymic function quantification. TRECs are circular episomal DNA discarded through TCR rearrangement processes that can only be thymically produced and lack of replication origin (they cannot be copied in periphery). Signal-joint (sj)-TREC quantification, discarded product of the achain rearrangement at DP stage, was described as a new thymic output-related marker (Douek et al., 1998). However, TREC counts are deeply affected by peripheral proliferation (Hazenberg et al., 2000), increasing the difficulty of interpretation (Harris et al., 2005). Moreover, subsequent mathematical models showed that, even in the steady state, the sjTREC content is not a good measurement of thymic function (Ribeiro and Perelson, 2007). To overcome these limitations, Dion et al. (2004) proposed an elegant technique to quantify the ratio between sj-TREC and the $\beta$-TRECs, discarded during the $\beta$-chain rearrangement at a more immature stage (see Figure 2). A proliferation step, directly related to thymic function, occurs between the $\beta$ - and the a-chain rearrangement. Thus, the $\mathrm{sj} / \beta$-TREC ratio is an indirect measure of this intrathymic proliferation step and a thymic function-related marker. In addition, since the proportion between both TREC types is evaluated, rather than TREC numbers, the results are not affected by peripheral proliferation, even if absolute TREC numbers are. Recently, we have described a simplified version of this technique that allows an accurate and time- and cost-effective quantification of human thymic function from peripheral blood samples (Ferrando-Martínez et al., 2010b). Table 1 summarizes different techniques that have been used to determine thymic function together with their advantages and disadvantages.

\section{Thymic function and age}

Thymus functionality starts during fetal life and is maximal at birth. After the first year of life, thymus goes through a chronic atrophy that progressively diminishes its function, eventually leading to thymic function exhaustion in later life. During this process TES loses the cortical/medullar architecture, lymphoid components are greatly reduced and TCR rearrangement is somehow impaired. Besides, TES is progressively reduced and this space is filled with adipocyte-packed PVS. Clinical implications of the age-related loss of thymic function and the specific burden of thymic output during different life-stages are still controversial. 


\begin{tabular}{|c|c|c|c|}
\hline Quantification method & Type & Advantages & Disadvantages \\
\hline $\begin{array}{l}\text { Double positive (DP) } \\
\text { thymocytes ex-vivo } \\
\text { quantification }\end{array}$ & $\begin{array}{l}\text { Thymic function- } \\
\text { related marker }\end{array}$ & $\begin{array}{l}\text { Thymic function } \\
\text { gold standard }\end{array}$ & $\begin{array}{l}\text { Needs thymic } \\
\text { biopsy }\end{array}$ \\
\hline Thymic volume & $\begin{array}{l}\text { Thymic function- } \\
\text { related marker }\end{array}$ & $\begin{array}{l}\text { Accurate indirect } \\
\text { approximation }\end{array}$ & $\begin{array}{l}\text { Irradiation }(\mathrm{CT}) \\
\text { Specifically trained } \\
\text { radiologist } \\
\text { Coarser } \\
\text { quantification }\end{array}$ \\
\hline Naive T lymphocytes & $\begin{array}{l}\text { Thymic output- } \\
\text { related marker }\end{array}$ & $\begin{array}{l}\text { Peripheral blood } \\
\text { sample }\end{array}$ & $\begin{array}{l}\text { Cannot discriminate } \\
\text { long-lived naive TL } \\
\text { Controversy } \\
\text { regarding markers }\end{array}$ \\
\hline $\begin{array}{l}\text { CD31-expressing naive } \\
\text { T Lymphocytes }\end{array}$ & $\begin{array}{l}\text { Thymic output- } \\
\text { related marker }\end{array}$ & $\begin{array}{l}\text { Peripheral blood } \\
\text { sample } \\
\text { Short proliferative } \\
\text { history }\end{array}$ & $\begin{array}{l}\text { Quantifies a recent } \\
\text { thymic emigrant } \\
\text { (RTE)-enriched } \\
\text { subset rather than } \\
\text { RTEs }\end{array}$ \\
\hline $\begin{array}{l}\text { PTK7-expressing T } \\
\text { lymphocytes }\end{array}$ & $\begin{array}{l}\text { Thymic output- } \\
\text { related marker }\end{array}$ & $\begin{array}{l}\text { Peripheral blood } \\
\text { sample } \\
\text { Immature naive TL }\end{array}$ & $\begin{array}{l}\text { Quantifies a recent } \\
\text { thymic emigrant } \\
\text { (RTE)-enriched } \\
\text { subset rather than } \\
\text { RTEs }\end{array}$ \\
\hline sjTREC quantification & $\begin{array}{l}\text { Thymic output- } \\
\text { related marker }\end{array}$ & $\begin{array}{l}\text { Peripheral blood } \\
\text { sample } \\
\text { Intrathymic } \\
\text { generation }\end{array}$ & $\begin{array}{l}\text { Deeply affected by } \\
\text { peripheral } \\
\text { proliferation }\end{array}$ \\
\hline sj/ $\beta$-TREC ratio & $\begin{array}{l}\text { Thymic function- } \\
\text { related marker }\end{array}$ & $\begin{array}{l}\text { Peripheral blood } \\
\text { samples } \\
\text { Intrathymic } \\
\text { generation } \\
\text { Not affected by } \\
\text { peripheral } \\
\text { proliferation }\end{array}$ & Technically difficult \\
\hline
\end{tabular}

Table 1. Advantages and disadvantages of the different thymic function quantification methods

\subsection{Thymic failure during childhood}

Thymus is the major site of TL maturation and, therefore, essential for the adaptive immune system formation. Few clinical situations involve lack of thymus, but all they lead to serious consequences. 


\subsubsection{DiGeorge syndrome: Defective thymic development}

DiGeorge syndrome is a congenital malformation involving defective development of the structures derived from the third and fourth pharyngeal pouch during fetal life, as thymus and parathyroid glands, among others. Depending on the severity of the syndrome, thymus can be completely absent or just reduced or misplaced. When thymus is present, thymic structure and functionality, despite reduced, is normal. Approximately $90 \%$ of all DiGeorge syndromes present a specific deletion on the region q11.2 of chromosome 22, while the remaining $10 \%$ show other chromosomic defects due to gestational diabetes, fetal alcoholism syndrome or prenatal exposure to Accutane ${ }^{\circledR}$ (cystic acne treatment). A similar defect in thymic development has been reported when mutation in gene $\mathrm{T}$ box 1 (TBX1) occurs. Principal characteristics of the DiGeorge syndrome are shown in Table 2.

\begin{tabular}{ll}
\hline \hline $\begin{array}{l}\text { Immune system } \\
\text { alterations }\end{array}$ & Aplasia or hypoplasia of thymus \\
& $\begin{array}{l}\text { Lymphocyte counts under } 1500 \text { cells / } \mu \mathrm{L} \\
\text { T lymphocytes absent or greatly reduced } \\
\text { T lymphocyte irresponsiveness to polyclonal T cell activators } \\
\text { and mixed lymphocyte reactions (MLRs) } \\
\text { Immunoglobulin levels and antibody function about normal } \\
\text { (may be reduced in severely affected patients) }\end{array}$ \\
& Susceptible to mycobacterial, viral and fungal infections \\
\hline Infectious diseases & Frequent congenic cardiac illness \\
\hline Cardiac affectations & Characteristic facial abnormalities \\
\hline Aesthetic affectations & Aplasia or hypoplasia of the parathyroid glands \\
\hline Others & Hypocalcemia \\
\hline \hline
\end{tabular}

Table 2. Clinical features of DiGeorge syndrome.

Most urgent treatment for children with DiGeorge syndrome is Pneumocistiis jirovenci prophylaxis. General care includes treating hypocalcemia and correcting cardiac abnormalities. When TL immunity is severely compromised, thymus and bone marrow transplant can partially restore the adaptive immune system. Severe syndromes usually lead to sudden or cardiac-derived death. Surprisingly, less severe syndromes, where TL are reduced but not absent, natural improvement due to regrowth of remaining thymic tissue, extra-thymic TL maturation or ectopic thymus development can be observed.

\subsubsection{Infectious ablation of the thymus}

Human immunodeficiency virus (HIV)-infected children usually show faster AIDS progression than their adult counterparts. Newborns infected during fetal development (intra-uterine infection versus infection in the birth canal) show important immune alterations from the first day of life. Due to lack of thymic function measurements, thymus ablation was defined thru peripheral observations as T lymphopenia involving both CD4 and CD8 T cell subsets. More severe thymic deficiency was associated with worse clinical prognosis. Some of these vertically-infected children present an immunophenotypic profile even comparable with DiGeorge syndrome. Infectious thymus ablation is strongly correlated with earlier and faster AIDS progression (Kourtis et al., 1996) and increased 
mortality rates (Nahmias et al., 1998) when compared with children with preserved thymic function (usually infected at the birth canal).

\subsection{Thymic failure during adulthood and elderly}

Atrophy implies thymic function reduction and it has been long time assumed that TL repertory was fixed during childhood and the thymus was no longer needed during adult life. However, different studies showed that adult thymus not only is functional but it can even booster its function to expedite immune reconstitution in different scenarios as chemotherapy (Mackall et al., 1995) or HIV-infected patients under highly active antiretroviral therapy (HAART) (de la Rosa and Leal, 2003).

During elderly, thymus shows even more reduced functionality. However, despite TES reduction and architectural changes, elderly thymus is able to maintain a certain degree of thymopoiesis (Jamieson et al., 1999). Thymopoietic degree is widely heterogeneous among individuals (Figure 3). In addition, thymic function in elderly people has an active role in the peripheral immune system rejuvenation (Ferrando-Martínez et al., 2009). Higher thymic function in elderly human is associated with a better preservation of the immune system. To add "insult to injury", thymic failure in healthy elderly leads to a discrete lymphopenia and naive $\mathrm{T}$ cell drop that eventually allows non-antigen driven homeostatic proliferation (Ferrando-Martinez et al., 2011). Homeostatic proliferation correlates with naive TL gathering age-related defects leading to irresponsiveness. Despite causality still needs to be assessed, altogether these results strongly suggest that elderly thymic function preservation or rejuvenation could be of great importance to ameliorate the age-related immune system deterioration. In fact, recent results show that thymic function, accurately measured with the $\mathrm{sj} / \beta$-TREC ratio quantification method, in healthy elderly subjects (aged over 65) is independently associated with two-years all-cause mortality (Ferrando-Martínez et al., 2011b).Thus, elderly thymic function still has an active role in the maintenance of the immune system and this information should be taken into account to design innovative therapies capable of improve elderly quality of life through the immune system rejuvenation.

\section{Surgical thymic ablation}

Thymus anatomically locates in the anterior mediastinum, just behind the sternum, facing the heart and the great vessels. This location places the thymus in the surgical field of critical open heart surgery. Since short-time consequences of either children or adult thymectomy have not been reported, thymus is partially or completely removed during this surgical procedure. However, recent studies suggest that individuals thymectomized during early childhood could have an immunological misbalance later on adulthood. Despite still a controversial topic, a continuously increasing body of knowledge supports the choice of preserving, as far as possible, thymus integrity.

\subsection{Neonatal thymectomy during congenital heart disease correction}

Congenital heart disease (CHD) comprises aberrant embryonic development or failure to progress beyond some early stage during fetal development of any cardiac structure. Septal or cyanotic defects, defects causing obstruction in either the heart or blood vessels and complex abnormalities are encompassed into CHD. Complex multifactorial genetic and environmental causes, rather chromosomal aberrations or single gene mutation (less than 


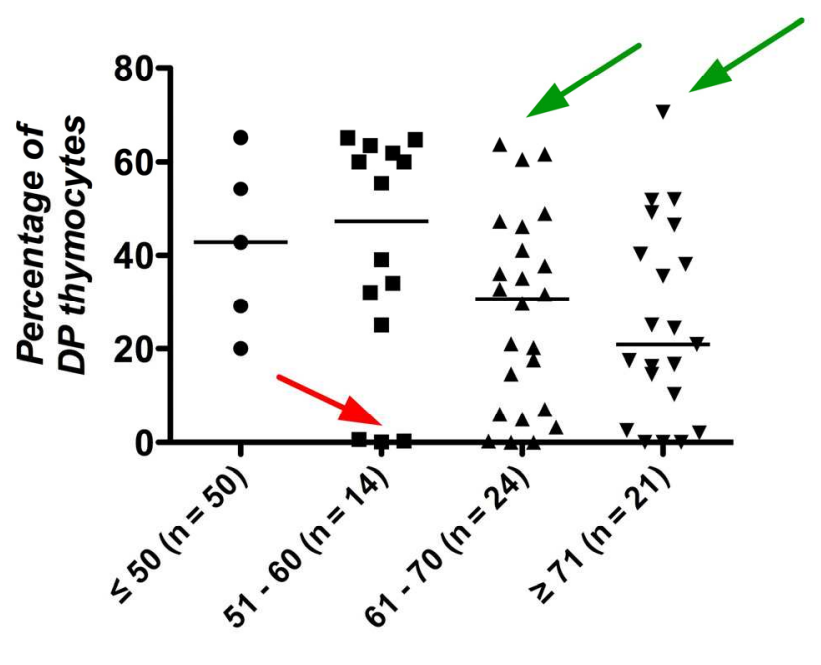

Age groups (years)

Fig. 3. Heterogeneity of the thymic function. Functionality was measured by ex-vivo quantification of DP thymocytes. Green arrows show high thymic function among elderly individuals (older than 65) while the red arrow show lack of functionality in adult individuals (50 to 60 years old). Modified from Ferrando-Martinez et al., 2009.

$10 \%$ of diagnosed CHD), are the origin this disease. Prevalence in general population is estimated in $1 \%$ of all live deliveries. However, frequency rises up to $4 \%$ for childbirths of women which have been diagnosed with CHD during childhood. Disorders showing mild seriousness usually need little or no medical treatment lifetime. However, CHD can be a life-threatening condition. Since CHD is a progressive disease from prenatal to adulthood, severe conditions can be lethal immediately after birth and also during child/adulthood. Deathly forms of CHD usually need invasive surgery to guarantee the patient's survival. All forms together, more than $85 \%$ of diagnosed newborns reach adulthood thanks to positive adaptation to their condition (non-severe forms) or to successful medical and surgical interventions (lethal forms). Over the last 30 years, neonatal surgery to correct serious CHD has become usual and, since surgical access is obstructed by the thymus, thymectomy is a common practice.

Several studies, with case-control designs, assessed the potential immune failure of thymectomyzed children. Despite data are scarce and methodology heterogeneous, some conclusion can be already extracted. When short-term consequences are analyzed (less than one year after surgery) low peripheral lymphocyte counts are already reported (Wells et al., 1998; Turan et al., 2004). From the lymphocyte populations, $\mathrm{T}$ cells are preferentially decreased. Normal responsiveness to mitogens and none clinical consequence have been reported despite the described lymphopenia. Other studies focused in children that underwent surgery one to five years before, in order to analyze medium-term consequences of thymectomy. The fast drop of the lymphocyte populations was still observed, suggesting 
that peripheral homeostasis is not enough to maintain normal lymphocyte numbers during childhood (Halnon et al., 2005; Mancebo et al., 2006). In addition, low sj-TREC levels are also associated with thymectomy. Low levels of sj-TREC per million of cells in the thymectomyzed group has been associated with insufficient thymic function. Therefore, despite thymectomy is only partial in some individuals and thymic regeneration could be observed in some reoperated children, the general appreciation is that remaining thymopoietic degree will never reach normal levels in early thymectomyzed individuals. However it should be noted that sj-TREC counts are not a good measure of thymic function, especially when high peripheral proliferation is involved. On account of thymectomyzed individuals evidence low lymphocyte counts early after the surgical procedure, it can be assumed that homeostatic-driven proliferation will try to adjust lymphopenia to normal levels. High proliferation rates will dilute the sj-TREC content, disregarding changes of thymic function. Consequently, even if inefficient thymic function is indisputable due to persistently low lymphocyte counts, thymic function dynamics need to be further analyzed. It is noteworthy that medium-time costs of thymectomy still do not involve any clinical consequence.

In addition, long-term consequences should be evaluated. Interestingly, long-term studies also report persistent lymphopenia (preferentially $\mathrm{T}$ lymphocyte drops, as expected) and maintained low sj-TREC levels. However, when 20 to 30 years old individuals are analyzed, a trend to normalization in naive TL is observed, despite not in all studies. On the other hand Eysteinsdottir et al., 2004 reported new immune defects, as impaired Th2 T cell response despite normal Th1 response. In this study, thymectomyzed subjects also present higher numbers of neutrophils and low platelet counts but normal B lymphocyte and natural killer (NK) cell numbers. Low naive T cell counts, high proliferation rates among the naive subset and increased IL-7 bioavailability have been also observed (Prelog et al., 2009). This later result is especially interesting, since this naive $\mathrm{T}$ lymphocytes alteration is also a hallmark feature of immune senescence on healthy aging (Ferrando-Martínez et al., 2011). Whether this non-antigen driven proliferation is also leading to a naive $\mathrm{T}$ cell pool exhaustion (described in age-related changes of naive TL) needs to be explored.

Accordingly, more recent works specifically focused on premature aging. Immune senescence, or immunosenescence, comprises the age-related changes of the immune system that gather phenotypic and functional defects in both, the innate and adaptive immune response. It is generally accepted that thymic atrophy, as the first age-related change, triggers the accumulation of lymphocyte frailty. Despite causality needs to be established, the prevalence and severity of infectious diseases, probable direct immunosenescence consequence, discloses de outstanding importance of the age-related immune exhaustion. Immune senescence has also been linked to lack of vaccination response, autoimmunity and increase in oncological pathology in elderly subjects. Other clinical situations involving immune weakness (as HIV-infection or immune reconstitution after extensive chemotherapy) have been analyzed under this point of view, interestingly finding that TL which are forced to replenish a strongly damaged immune space usually show premature immunosenescence-related defects. Thymic function defects in early childhood can be an added model of premature immunosenescence. In this regard, thymectomyzed children show several features usually reported in chronological immunosenescence. Naive TL have increased proliferation rates, strong oligoclonal CMV-specific responses (that probably can accumulate because thymus is not able to replenish the immune space with 
naive TL), CD57-expressing exhausted cells or systemic inflammation biomarkers (Sauce et al., 2009). Lack of vaccine response, as elderly individuals, seems to focus on new antigens, despite normal memory responses (Zlamy et al., 2010). As a difference, thymectomyzed children have delayed vaccine response, rather that complete lack of immunization.

Finally, some studies report about normal TL counts after 20 - 30 years post-thymectomy, suggesting a reestablishment of thymic function later on life. Van Gent et al. (2011) report normal naive $\mathrm{T}$ cell numbers, adjusted proliferation rates and sj-TRECs numbers, concluding that thymectomization has an early impact on the LT compartment that will be restored later on life. Thymic regeneration (as measure by image techniques and inferred by sj-TREC dynamics) is proposed as major restoration mechanism. The reason why some cohorts can observe thymic and LT renewal (van Gen et al., 2011) while other do not (Prelog et al., 2009), remains a matter of debate. Partial results and animal models point to the possibility that younger thymus (months after birth) could have higher epithelial precursor content and, then, higher regeneration potential. However, further studies are needed to better clarify whether thymus actually have an age-related drop of regeneration capability. The lack of clinical consequences reported by all studies could be explained by thymic renewal and immune system restoration during adulthood. Despite all these results are very reassuring, it should be note that thymectomyzed individuals grow up with a frail immune system the first five to ten years of life and premature immunosenescence features have been reported in young adulthood ( 20 - 30 years old), suggesting that early thymectomy have immune consequences that, despite not being overwhelming, could have clinical consequences once premature immunosenescence joins the age-related exhaustion of the immune system.

\subsection{Adult thymectomy: Open heart surgery}

Valve replacement and ischemic cardiopathy are common open heart surgical procedures in adulthood / elderly subjects. Despite neonatal thymus size is larger than the atrophied adult thymus is; thymectomy to gain unrestricted view of the operation site is performed at any age. Moreover, the widespread belief that thymus from adult individuals completely lacks of functionality makes it usually despised. Anyhow, several factors should be pondered. First of all, despite the atrophy, elderly thymus still impacts on the peripheral $\mathrm{T}$ cell pool rejuvenation (Ferrando-Martínez et al., 2009). The more important, thymic function failure, in subjects over 65, predicts two-year all-cause mortality (Figure 4) (Ferrando-Martínez et al., 2011b). Moreover, myasthenia gravis patients (neuromuscular autoimmune disease where thymectomy is associated with better prognosis by unknown mechanisms) benefit of complete thymectomy even if thymus is already atrophied (Chen et al., 2011). All results together strongly suggest that atrophied thymus is active in different ways rather than an inactive surplus.

In addition, immune system of adult and elderly subjects undergoing open heart surgery already present exhaustion and senescence features. Thus, short- and medium-time defects induced by thymectomy (clearly present in children up to five to ten years old) will be acting on a previously damaged system. Clinical consequences of this damage have not been studied yet. Associated comorbidities of an elderly cohort with major cardiac illness is not easy, but further studies are needed to evaluate the potential effect of thymus removal on survival rates. 


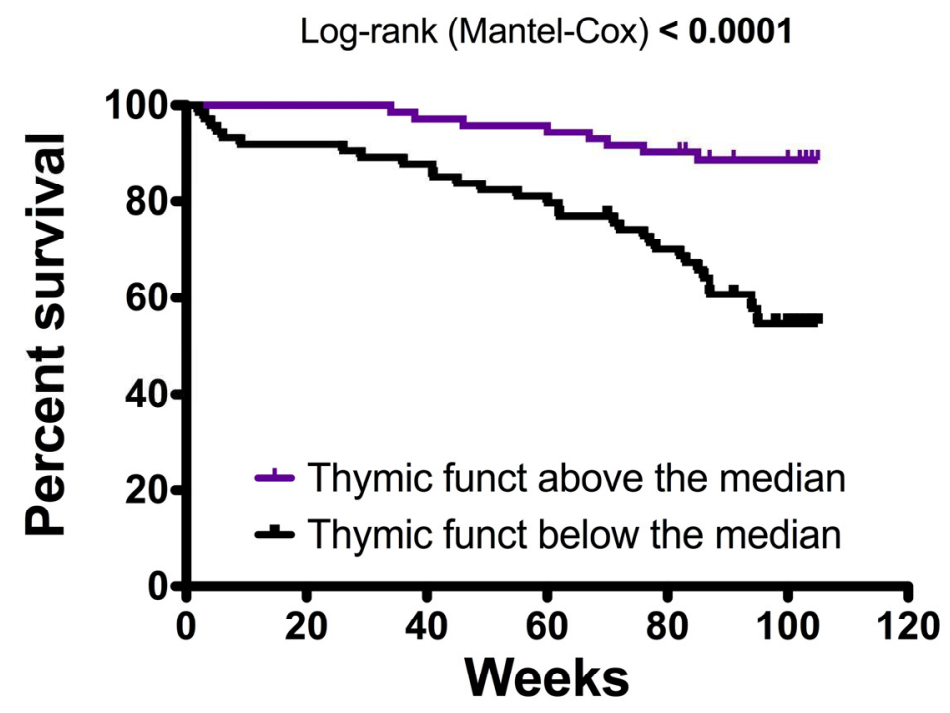

Fig. 4. Relationship between thymic function and two-year all-cause mortality in healthy elderly. Modified from Ferrando-Martínez et al., 2011b.

\section{Conclusions and recommendations}

Neonatal thymectomy have immunological consequences in short- and medium-time, despite these defects are not associated with clinical outcomes. $\mathrm{T}$ lymphocytes show a trend to normalization and stabilization in long-term analysis. Normalization could be due to thymic tissue regeneration. However, several features of exhaustion and senescence are detected in young adults 20 years old that underwent thymectomy in the first year of life. Premature immunosenescence is not found in age-matched nonthymectomized controls. In a reassuring way, despite the immune response to newly encountered antigens is delayed, clinical consequences (increased infection rates or other clinical signs of immune weakness) are not observed at any age. Subsequent studies are needed to determine the consequences, if any, of the thymectomy-induced premature senescence once chronological immunosenescence starts exhausting the immune system. On the other hand, elderly thymectomy data is still missing, but information showing that thymus still has relevance in seniors strongly suggest the need of caution before performing complete thymectomy: thymus removal in elderly individuals aggravates a previously frail immune system.

The topic remains controversial, and strong data are still scarce. Moreover, open heart surgery is an important procedure with priority over an immunosenescent scenario. However, our recommendation in children's surgery, where the great size of the thymus forces the surgeon to resect to gain unrestricted view of the operation site, is to proactively preserve the maximum possible tissue. During interventions of adult or elderly patients, which atrophied thymus is no longer a critical problem to reach the surgical field; our 
recommendation is to preserve the complete organ to guarantee the maximal integrity of the immune system.

\section{Acknowledgements}

Authors want to thank the cardiac surgery team of the Virgen del Rocío University Hospital. Their support and interest in Immunology research have been critical for us. Similarly, we are thankful to Dr. Felipe Borderas and the Service of Anatomical Pathology of the HUVR as key help with H\&E slides preparation and interpretation. This work has been supported by Red de Investigación en SIDA (ISCIII RETIC RD06/0006/0021 and RD06/0006/0035).

\section{References}

Chen, Z.; Luo, H.; Peng, Y.; Cai, L.; Zhang, J.; Su, C. and Zou, J. (2011). Comparative clinical features and immune responses after extended thymectomy for myasthenia gravis in patients with atrophic versus hyperplastic thymus. The Annals of Thoracic Surgery, Vol.91 No.1, pp.212-218

Chiodi, H. (1940). The relationship between the thymus and the sexual organs. Endocrinology, Vol.26, No.1, pp.107-116

De la Rosa, R. \& Leal, M. (2003). Thymic involvement in immune recovery among chronicHIV-infected adults under highly active antiretroviral therapy. Journal of Antimicrobial therapy, Vol.52, No.2, pp.155-158

Dion, M.L.; Poulin, J.F.; Bordi, R.; Sylvestre, M.; Corsini, R.; Kettaf, N.; Dalloul, A.; Boulassel, M.R.; Debré, P.; Routy, J.P.; Grossman, Z.; Sekaly, R.P. \& Cheynier, R. (2004). HIV infection rapidly induces and maintains a substantial suppression of thymocyte proliferation. Immunity, Vol.21, No.6, pp.757-768

Douek, D.C.; McFarland, R.D.; Keiser, P.H.; Gage, E.A.; Massey, J.M.; Haynes, B.F.; Polis, M.A.; Haase, A.T.; Feinberg, M.B.; Sullivan, J.L.; Jamieson B.D.; Zack, J.A.; Picker, L.J. \& Koup, R.A. (1998). Changes in thymic function with age and during the treatment of HIV infection. Nature, Vol.396, No.6712, pp.690-695

Eysteinsdottir, J.H.; Freysdottir, J.; Haraldsson, A.; Stefansdottir, J.; Skaftadottir, I.; Helgason, H. \& Ogmudsdottir, H.M. (2004). The influence of partial or total thymectomy during open heart surgery in infants on the immune function later on life. Clinical and Experimental Immunology, Vol. 136, No.2, pp.349-355

Ferrando-Martínez, S.; Franco, J.M.; Hernández, A.; Ordóñez, A.; Gutiérrez, E.; Abad, A. \& Leal, M. (2009). Thymopoiesis in elderly human is associated with systemic inflammatory status. Age (Dodr), Vol.31, No.2, pp.87-97

Ferrando-Martínez, S.; Ruiz-Mateos, E. \& Leal, M. (2010) CD27 and CCR7 expression on naive T cells: are both necessary? Immunology Letters, Vol.127, No.2, pp.157-158

Ferrando-Martínez, S.; Franco, J.M.; Ruiz-Mateos, E.; Hernández, A.; Ordoñez, A.; Gutiérrez, E. \& Leal, M. (2010b). A reliable and simplified sj/ $\beta$-TREC ratio quantification method for human thymic output measurement. Journal of Immunological Methods, Vol.352, No.1-2, pp.111-117 
Ferrando-Martínez, S.; Ruiz-Mateos, E.; Hernández, A.; Gutiérrez, E.; Rodríguez-Méndez, M.M.; Ordoñez, A. \& Leal M. (2011). Age-related deregulation of naive T cell homeostasis in elderly humans. Age (Dodr), Vol.33, No.2, pp.197-207

Ferrando-Martínez, S.; Romero-Sánchez, M.C.; Delgado, J.; de la Rosa, R.; Solana, R.; RuizMateos, E. \& Leal, M. (2011b). Thymic function and inflammation markers are independently associated with elderly human survival rates. VII IAGG European congress, "Healthy and active ageing for all Europeans - II", Bologna, April 2011 (oral communication)

Haines, C.J.; Giffon, T.D.; Li-Sheng, L.; Lu, X.; Tessier-Lavigne, M.; Ross, D.T. \& Lewis, D.B. (2009). Human CD4+ T cell recent thymic emigrants are identified by protein tyrosine kinase 7 and have reduced immune function. Journal of Experimental Medicine, Vol.206, No.2, pp.275-285

Halnon, N.J.; Jamieson, B.; Plunkett, M.; Kitchen, C.M.; Pham, T. and Krogstad, P. (2005). Thymic function and impaired maintenance of peripheral $\mathrm{T}$ cell populations in children with congenital heart disease and surgical thymectomy. Pediatric Research, Vol.57, No.1, pp.42-48

Harris, J.M.; Hazenberg, M.D.; Poulin, J.F.; Higuera-Alhino, D.; Schmidt, D.; Gotway, M. \& McCune, J.M. (2005). Multiparameter evaluation of human thymic function: interpretation and caveats. Clinical Immunology, Vol.115, No.2, pp.138-146

Hazenberg, M.D.; Otto, S.A.; Cohen Stuart, J.W.; Verschuren, M.C.; Borleffs, J.C.; Boucher, C.A.; Coutinho,R.A.; Lange, J.M.; Rinke de Wit, T.F.; Tsegaye, A.; von Dengen, J.J.; Harmann, D.; de Boer, R.J. \& Miedema, F. (2000). Increased cell division but not thymic dysfunction rapidly affects the $\mathrm{T}$ cell receptor excision circle content of the naive T cell population in HIV-1 infection. Nature Medicine, Vol.6, No9, pp.10361042

Jamieson, B.D.; Douek, D.C.; Killian, S.; Hultin, L.E.; Scripture-Adams, D.D.; Giorgi, J.V.; Marellin D.; Koup R.A. \& Zack, J.A. (1999). Generation of functional thymocytes in the human adult. Immunity, Vol.10, No.5, pp.569-575

Junge, S.; Kloeckener-Gruissem, B.; Zufferey, R.; Keisker, A.; Salgo, B.; Fauchere, J.C.; Scherer, F.; Shalaby, T.; Grotzer, M.; Seger, R. \& Güngör, T. (2007). Correlation between recent thymic emigrants and CD31+ (PECAM-1) CD4+ T cells in normal individuals during aging and in lymphopenic children. European Journal of Immunology, Vol.37, No.11, pp.3270-3280

Kourtis, A.P.; Ibegbu, C.; Nahmias, A.J.; Lee, F.K.; Clark, W.S.; Sawyer, M.K \& Nesheim, S. (1996). Early progression of disease in HIV-infected infants with thymus dysfunction. New England Journal of Medicine, vol.335, No.19, pp.1431-1436

Lynch, H.E.; Goldberg, G.L.; Chidgey, A.; Van den Brink, M.R.M.; Boyd, R. \& Sempowski, G.D. (2009). Thymic involution and immune reconstitution. TRENDS in Immunology, Vol. 30, No.7, pp.366-373

Mackall, C.L.; Fleisher, T.A.; Brown, M.R.; Andrich, M.P.; Chen, C.C.; Feuerstein, I.M.; Horowitz, M.E.; Magrath, I.T.; Shed, A.T.; Steinberg, S.M.; Wexler, L.H. \& Gress, R.E. (1995). Age, thymopoiesis and CD4+ T-lymphocyte regeneration after 
intensive chemotherapy. New England Journal of Medicine, Vol.332, No.3, pp.143149

Mancebo, E.; Clemente, J.; Sanchez, J.; Ruiz-Contreras, J.; De Pablos, P.; Cortezon, S.; Romo, E.; Paz-Artal, E. and Allende, L.M. (2008). Longitudinal analysis of immune function in the first 3 years of life in thymectomyzed neonates during cardiac surgery. Clinical and Experimental Immunology, Vol.154, No.3, pp.375-383

Nahmias, A.J.; Clark, W.S.; Kourtis, A.K.; Lee, F.K.; Cotsonis, G.; Ibegbu, C.; Thea, D.; Palumbo, P.; Vink, P.; Simonds, R.J.; Nesheim, S.R. \& the CDC Perinatal AIDS Collaborative Transmission Study Group. (1998). Thymic dysfunction and time of infection predict mortality in human immunodeficiency virus-infected infants. The Journal of Infectious Diseases, Vol.178, No.3, pp.680-685

Prelog, M.; Keller, M.; Geiger, R.; Brandstätter, A.; Würzner R.; Schweigmann, U.; Zlamy, M.; Zimmerhackl, L.B. \& Grubeck-Loebenstein, B. (2009). Thymectomy in early childhood: significant alterations of the CD4(+)CD45RA(+)CD62L $(+)$ T cell compartment in later life. Clinical Immunology, Vol.130, No.2, pp.123-132

Ribeiro, R.M. \& Perelson, A.S. (2007). Determining thymic output quantitatively: using models to interpret experimental T-cell receptor excision circle (TREC) data. Immunological Reviews, Vol.216, pp.21-34

Ruiz-Mateos, E.; Rubio, A.; Vallejo, A.; de la Rosa, R.; Sánchez-Quijano, A.; Lissen, E. \& Leal, M. (2004). Thymic volume is associated independently with the magnitud of shortand long-term repopulation of CD4+ T cells in HIV-infected adults after highly active antiretroviral therapy (HAART). Clinical and Experimental Immunology, Vol.136, No.3, pp.501-506

Sauce, D.; Larsen, M.; Fastenackels, S.; Duperrier, A.; Keller, M.; Grubeck-Loebestein, B.; Ferrand, C.; Debré, P.; Sidi, D. \& Appay, V. (2009). Evidence of premature immune aging in patients thymectomyzed during early childhood. Journal of Clinical Investigation, Vol.119, No.10, pp.3070-3078

Sempowski, G.D.; Hale, L.P.; Sundy, J.S.; Massey, J.M.; Koup, R.A.; Douek, D.C.; Patel, D.D. \& Haynes, B.F. (2000). Leukemia inhibitory factor, oncostatin M, IL-6 and stem cell factor mRNA expression in human thymus increases with age and is associated with thymic atrophy. Journal of Immunology, Vol.164, No.4, pp.2180-2187

Steinmann, G.G.; Klaus, B. \& Müller-Hermelink, H.K. (1985). The involution of the ageing human thymic epithelium is independent of puberty. A morphometric study. Scandinavian Journal of Immunology, Vol.22, No.5, pp.563-575

Turan, T.; Turan, M.; Arslan, C.; Kinoglu, B. and Sarioglu, T. (2004). How does neonatal thymectomy affect the immune system? Acta Cardiologica, Vol.59, No.5, pp.511513

Van Gent, R.; Schadenberg, A.W.L.; Otto, S.A.; Nievelstein, R.A.J.; Sieswerda, G.T.; Haas, F.; Miedema, F.; Tesselaar, K.; Jansen, N.J.G. \& Borghans, J.A.M. (2011). Longterm restoration of the human T-cell compartment after thymectomy during infancy: a role for thymic regeneration? Blood, in press (DOI: 101182/blood-201103-341396) 
Wells, W.J.; Parkman, R.; Smogorzewska, E. \& Barr, M. (1998). Neonatal thymectomy: does it affect immune function? The Journal of Thoracic and Cardiovascular Surgery, Vol.115, No.5, pp.1041-1046

Zlamy, M.; Würzner, R.; Holzmann, H.; Brandstätter, A.; Jeller, V.; Zimmerhackl, L.B. \& Prelog, M. (2010). Antibody dynamics after tick-born encephalitis and measlesmumps-rubella vaccination in children post early thymectomy. Vaccine, Vol.28, No.51, pp.8053-8060 


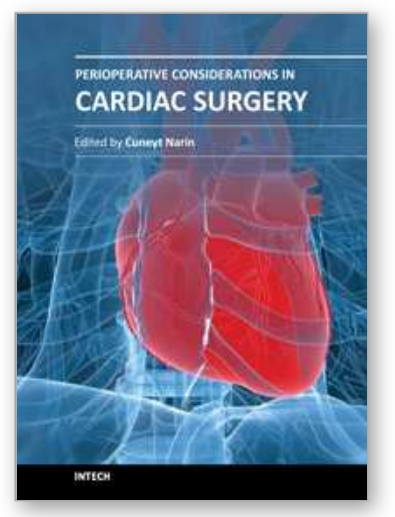

\author{
Perioperative Considerations in Cardiac Surgery \\ Edited by Prof. Cuneyt Narin
}

ISBN 978-953-51-0147-5

Hard cover, 378 pages

Publisher InTech

Published online 29, February, 2012

Published in print edition February, 2012

This book considers mainly the current perioperative care, as well as progresses in new cardiac surgery technologies. Perioperative strategies and new technologies in the field of cardiac surgery will continue to contribute to improvements in postoperative outcomes and enable the cardiac surgical society to optimize surgical procedures. This book should prove to be a useful reference for trainees, senior surgeons and nurses in cardiac surgery, as well as anesthesiologists, perfusionists, and all the related health care workers who are involved in taking care of patients with heart disease which require surgical therapy. I hope these internationally cumulative and diligent efforts will provide patients undergoing cardiac surgery with meticulous perioperative care methods.

\title{
How to reference
}

In order to correctly reference this scholarly work, feel free to copy and paste the following:

Sara Ferrando-Martínez, M. Ángeles Muñoz-Fernández and Manuel Leal (2012). Sticking Up for the Immune System Integrity: Should the Thymus Be Preserved During Cardiac Surgery?, Perioperative Considerations in Cardiac Surgery, Prof. Cuneyt Narin (Ed.), ISBN: 978-953-51-0147-5, InTech, Available from:

http://www.intechopen.com/books/perioperative-considerations-in-cardiac-surgery/sticking-up-for-the-immunesystem-integrity-should-the-thymus-be-preserved-during-cardiac-surgery-

\section{INTECH}

open science | open minds

\author{
InTech Europe \\ University Campus STeP Ri \\ Slavka Krautzeka 83/A \\ 51000 Rijeka, Croatia \\ Phone: +385 (51) 770447 \\ Fax: +385 (51) 686166 \\ www.intechopen.com
}

\author{
InTech China \\ Unit 405, Office Block, Hotel Equatorial Shanghai \\ No.65, Yan An Road (West), Shanghai, 200040, China \\ 中国上海市延安西路65号上海国际贵都大饭店办公楼 405 单元 \\ Phone: +86-21-62489820 \\ Fax: +86-21-62489821
}


(C) 2012 The Author(s). Licensee IntechOpen. This is an open access article distributed under the terms of the Creative Commons Attribution 3.0 License, which permits unrestricted use, distribution, and reproduction in any medium, provided the original work is properly cited. 